DOT/FAA/AM-02/9

Office of Aerospace Medicine Washington, DC 20591

\section{Relationship of Employee Attitudes and Supervisor- Controller Ratio to En Route Operational Error Rates}

Dana M. Broach

Carolyn S. Dollar

Civil Aerospace Medical Institute

Federal Aviation Administration

Oklahoma City, OK 73125

May 2002

Final Report

This document is available to the public

through the National Technical Information

Service, Springfield, VA 22161.

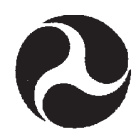

U.S. Department

of Transportation

Federal Aviation

Administration 


\section{$\mathrm{N} O \mathrm{~T}$ I C E}

This document is disseminated under the sponsorship of the U.S. Department of Transportation in the interest of information exchange. The United States Government assumes no liability for the contents thereof. 
Technical Report Documentation Page

\begin{tabular}{|c|c|c|c|c|}
\hline \multicolumn{3}{|l|}{$\begin{array}{l}\text { 1. Report No. } \\
\text { DOT/FAA/AM-02/9 }\end{array}$} & \multicolumn{2}{|c|}{ 3. Recipient's Catalog No. } \\
\hline \multirow{3}{*}{\multicolumn{3}{|c|}{$\begin{array}{l}\text { 4. Title and Subtitle } \\
\text { Relationship of Employee Attitudes and Supervisor-Controller Ratio } \\
\text { to En Route Operational Error Rates }\end{array}$}} & \multicolumn{2}{|l|}{ 5. Report Date } \\
\hline & & & \multicolumn{2}{|c|}{ May 2002} \\
\hline & & & \multicolumn{2}{|c|}{ 6. Performing Organization Code } \\
\hline \multicolumn{3}{|l|}{$\begin{array}{l}\text { 7. Author(s) } \\
\text { Broach, D., \& Dollar, C.S. }\end{array}$} & \multicolumn{2}{|c|}{ 8. Performing Organization Report No. } \\
\hline \multirow{2}{*}{\multicolumn{3}{|c|}{$\begin{array}{l}\text { 9. Performing Organization Name and Address } \\
\text { Training \& Organizational Research Laboratory } \\
\text { FAA Civil Aerospace Medical Institute } \\
\text { P.O. Box } 25082 \\
\text { Oklahoma City, OK } 73125\end{array}$}} & \multicolumn{2}{|c|}{ 10. Work Unit No. (TRAIS) } \\
\hline & & & \multicolumn{2}{|c|}{ 11. Contract or Grant No. } \\
\hline \multirow{2}{*}{\multicolumn{3}{|c|}{$\begin{array}{l}\text { 12. Sponsoring Agency name and Address } \\
\text { Office of Aerospace Medicine } \\
\text { Federal Aviation Administration } \\
800 \text { Independence Ave., S.W. } \\
\text { Washington, DC } 20591\end{array}$}} & \multicolumn{2}{|c|}{ 13. Type of Report and Period Covered } \\
\hline & & & \multicolumn{2}{|c|}{ 14. Sponsoring Agency Code } \\
\hline \multicolumn{5}{|c|}{$\begin{array}{l}\text { 15. Supplemental Notes } \\
\text { Work was accomplished under approved subtask AM-B-01-HRR516. }\end{array}$} \\
\hline \multicolumn{5}{|c|}{$\begin{array}{l}\text { 16. Abstract } \\
\text { An operational error (OE) results when an air traffic control specialist (ATCS) fails to maintain appropriate } \\
\text { separation between aircraft, obstacles, etc. Recent research on OEs has focused on situational and individual } \\
\text { characteristics (Center for Naval Analyses Corporation, 1995; Della Rocco, 1999; Rodgers, Mogford, Mogford, } \\
\text { 1998). In this study, the relationship of organizational factors to en route OE rates was investigated, based on } \\
\text { an adaptation of the Human Factors Analysis and Classification System (HFACS; Shappell \& Wiegmann, } \\
\text { 2000) to air traffic control as HFACS-ATC (Scarborough \& Pounds, 2001). OE rates (errors per 100,000 } \\
\text { operations) for } 1997 \text { and } 2000 \text { were obtained from the National Airspace Incident Monitoring System } \\
\text { (NAIMS) for } 21 \text { air route traffic control centers (ARTCC). Organizational factors were represented by facility } \\
\text { mean scores on scales constructed from } 1997 \text { and } 2000 \text { FAA Employee Attitude Survey (EAS) data. Factors } \\
\text { included employee perceptions of equipment/facilities, performance management, overall job satisfaction, and } \\
\text { perceptions of other human resources management practices. The supervisor-controller ratio (SCR) was } \\
\text { calculated for each ARTCC by year from agency personnel data. SCR and organizational factors facility mean } \\
\text { scores were regressed on OE rate ( } N=42 \text { ). Two organizational factors and SCR accounted for } 50 \% \text { (adjusted } R^{2} \\
=.505, p<.001 \text { ) of the variance in OE rates across ARTCCs for the two years. The standardized regression } \\
\text { coefficients were }-.290 \text { for perceptions of equipment/facilities }(t=-2.07, p<.05),-.302 \text { for perceptions of } \\
\text { performance management }(t=-2.28, p<.05) \text {, and -.395 for SCR ( } t=-3.360, p<.01 \text { ). As expected from prior } \\
\text { research, SCR was a significant predictor of en route OE rates. In addition, the results indicated that } \\
\text { perceptions of how performance was managed and of facilities and equipment were also predictors of OE rates. } \\
\text { Overall, the results support the inclusion of organizational factors as well as individual and situational } \\
\text { characteristics in the investigation of ATCS operational errors. }\end{array}$} \\
\hline \multicolumn{2}{|c|}{$\begin{array}{l}\text { 17. Key Words } \\
\text { Air Traffic Controllers, Job Attitudes, Operational Errors, } \\
\text { Human Factors, Performance, Psychology, Organizational } \\
\text { Characteristics }\end{array}$} & \multicolumn{3}{|c|}{$\begin{array}{l}\text { 18. Distribution Statement } \\
\text { Document is available to the public through the } \\
\text { National Technical Information Service, } \\
\text { Springfield, VA } 22161 .\end{array}$} \\
\hline 19. Security Classif. (of this report) & 20. Security Classif. (of this pag & & 21. No. of Pages & 22. Price \\
\hline & Unclassific & & & \\
\hline
\end{tabular}




\section{Relationship of Employee Attitudes and Supervisor-Controller Ratio to En Route Operational Error Rates}

Air traffic controllers ensure the safe, orderly, and expeditious flow of air traffic through the National Airspace System (NAS). To ensure the safety of flight, controllers maintain adequate separation between aircraft and obstacles to flight. They issue speed, altitude, and heading commands to pilots to provide and maintain required separation. An operational error (OE) results when an Air Traffic Control Specialist (ATCS, "air traffic controller," or "controller") fails to maintain appropriate separation between aircraft, terrain, and other obstacles to safe flight. The number of OEs per 100,000 facility activities ("OE rate") has long been an index of NAS safety. Reduction in the OE rate is a safety goal for the FAA "line-of-business" responsible for the delivery and management of air traffic services. For example, the Air Traffic Services Performance Plan FY2001-2003 (Air Traffic Services, 2000 ) calls for the reduction of OEs by $2.5 \%$ per year in FY2002 and FY2003.
However, the OE rate has increased in recent years. For example, the number of OEs increased from 754 in fiscal year (FY) 1997 to 1,194 in FY2001. The goal for FY2001 was 812 errors (Figure 1). The rate also increased, from .51 to .68 per 100,000 facility operations (Department of Transportation Office of the Inspector General, 2000, 2002). Explanations for the increase include better reporting and increased traffic. Possible situational and individual causal factors have been investigated in several studies (see, for examples, Broach, 1999; Della Rocco, Cruz, \& Clemens, 1999; Endlsey \& Rodgers, 1997; Rodgers \& Nye, 1993; Rodgers, Mogford, \& Mogford, 1998; Schroeder \& Nye, 1993). The Center for Naval Analyses Corporation (CNAC, 1995) examined the relationship of individual characteristics, staffing ratios, and facility characteristics to en route OEs for the period 1990 through 1995. There appeared to be little correlation between the supervisor-controller staffing ratio and

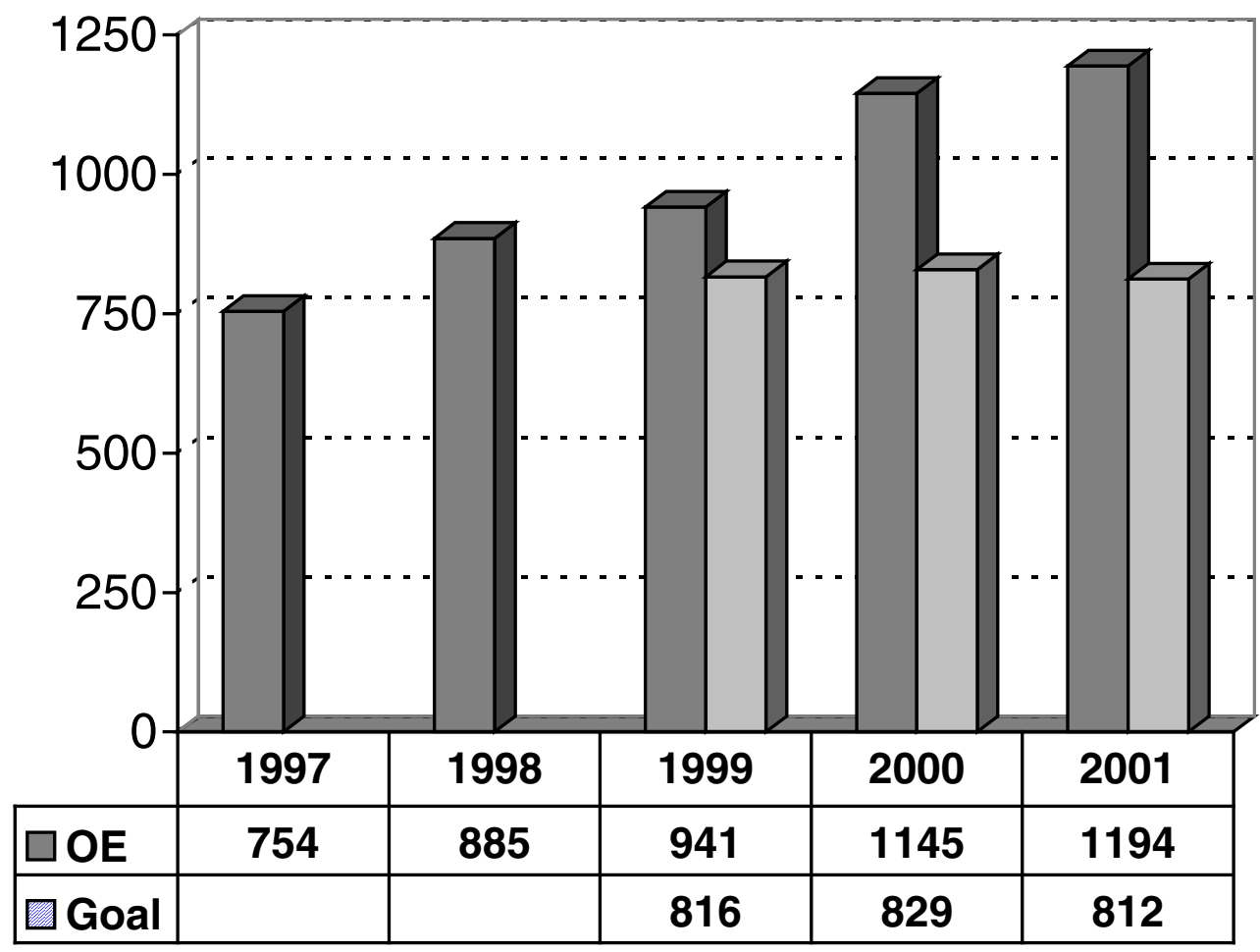

Figure 1: Actual operational errors (OE) and goal by fiscal year (Adapted From Department of Transportation Office of the Inspector General, 2002) 
the OE rate (p. 94). CNAC concluded that the number of OEs were primarily a function of the complexity of the sectors being supervised rather than individual characteristics of the supervisor (p. 97).

This study replicated and extended the CNAC study by focusing on the influence of organizational characteristics on $\mathrm{OE}$ rate at the 21 continental air route traffic control centers (ARTCCs, or centers). Organizational characteristics have been hypothesized to influence the occurrence of human errors (Reason, 1990; Shappell \& Wiegmann, 2000). Organizational characteristics in the Human Factors Classification and Analysis System-Air Traffic Control (HFACSATC; Scarborough \& Pounds, 2001) include (a) organizational climate, (b) organizational structure, (c) policies and procedures, and (c) resource management.

Organizational climate in HFACS-ATC refers to the working atmosphere within the organization. An organizational climate characterized by confusion and conflict may have a detrimental effect on safety (Shappell \& Wiegmann, p. 13). Job satisfaction, for example, might serve as an overall indicator of the organizational climate. Schneider (2001) investigated the relationship of job satisfaction to operational errors in the en route environment. Facility mean scores were computed for selected items from the FAA's 1997 Employee Attitude Survey (EAS). Schneider then correlated those scores with the number of OEs for each en route facility $(N=21)$. No significant correlations between operational errors and various measures of job satisfaction were found. Organizational structure refers to attributes such as the ratio of supervisors to controllers and the hierarchical organization of the facility. The 1995 CNAC study reported no significant correlation between $\mathrm{OE}$ rates and the ratio of supervisors to controllers. However, Fisher (2001) qualitatively linked reductions in the number of operational supervisors, an organizational structure characteristic, to increases in operational errors. Other facets of organizational structure might include the degree of oversight exercised over employees, and the accountability of management employees for performance. Policies and procedures in the HFACSATC refer to the broad class of corporate decisions and rules that structure everyday working life. Kinney (1977) qualitatively described how organizational policies influenced the occurrence of operational errors. However, no recent research has investigated the influence of organizational policies and procedures. Finally, resource management in HFACS-ATC encompasses the allocation of organizational assets such as personnel, money, and facilities or equipment. One aspect of resource management might be employee perceptions of the quality of equipment, the facility overall, and maintenance services. The purpose of the present study was to explore possible relationships between several of the organizational facets proposed by HFACS-ATC to OE rates in today's air traffic control system.

\section{METHOD}

\section{Data sources}

OE rates (errors per 100,000 operations) were obtained from the National Airspace Incident Monitoring System (NAIMS) for calendar years 1997 and 2000 for 21 U.S. ARTCCs. The combined en route/ approach control facilities in Guam, Hawaii, and Puerto Rico were excluded from the analysis as they are operationally different from the 21 continental air route traffic control centers. Response data for selected items from the EAS for the years 1997 and 2000 were used to construct the organizational factors used in this study. Staffing data for 1997 and 2000 were extracted from the FAA's Consolidated Personnel Management Information System (CPMIS), the agency's official system of personnel records.

\section{Organizational factors}

Items from the EAS for 1997 and 2000 were selected to represent the organizational factors hypothesized to influence operational errors in the HFACS-ATC model. The EAS is a broad instrument used to assess FAA employee perceptions of the workplace (Thompson, et al., 2000). Sufficient organizational demographic data were collected from each respondent to allow segmentation of the data by workforce and facility. The overall response rate from the 21 centers were $41 \%$ in 1997 and 33\% in 2000 . Centers have, on average, about 300 controllers, with the exception of Anchorage which has just over 200 controllers.

The mapping of 1997 and 2000 EAS items and scales to the HFACS-ATC organizational factors is shown in Table 1. Only items that had remained unchanged between the two EAS administrations were considered to ensure comparability across years. A measure of the internal consistency, known generally as Cronbach's alpha ( $\alpha$; Cronbach, 1951), or the degree to which the items were related to one another, was calculated for each set of items selected to represent a HFACS-ATC factor. Cronbach's $\alpha$ can be computed if there are at least two items in the scale. Higher values for Cronbach's $\alpha$ for a HFACS-ATC factor indicated greater consistency in responses to the items, while lower values indicated less consistency. 


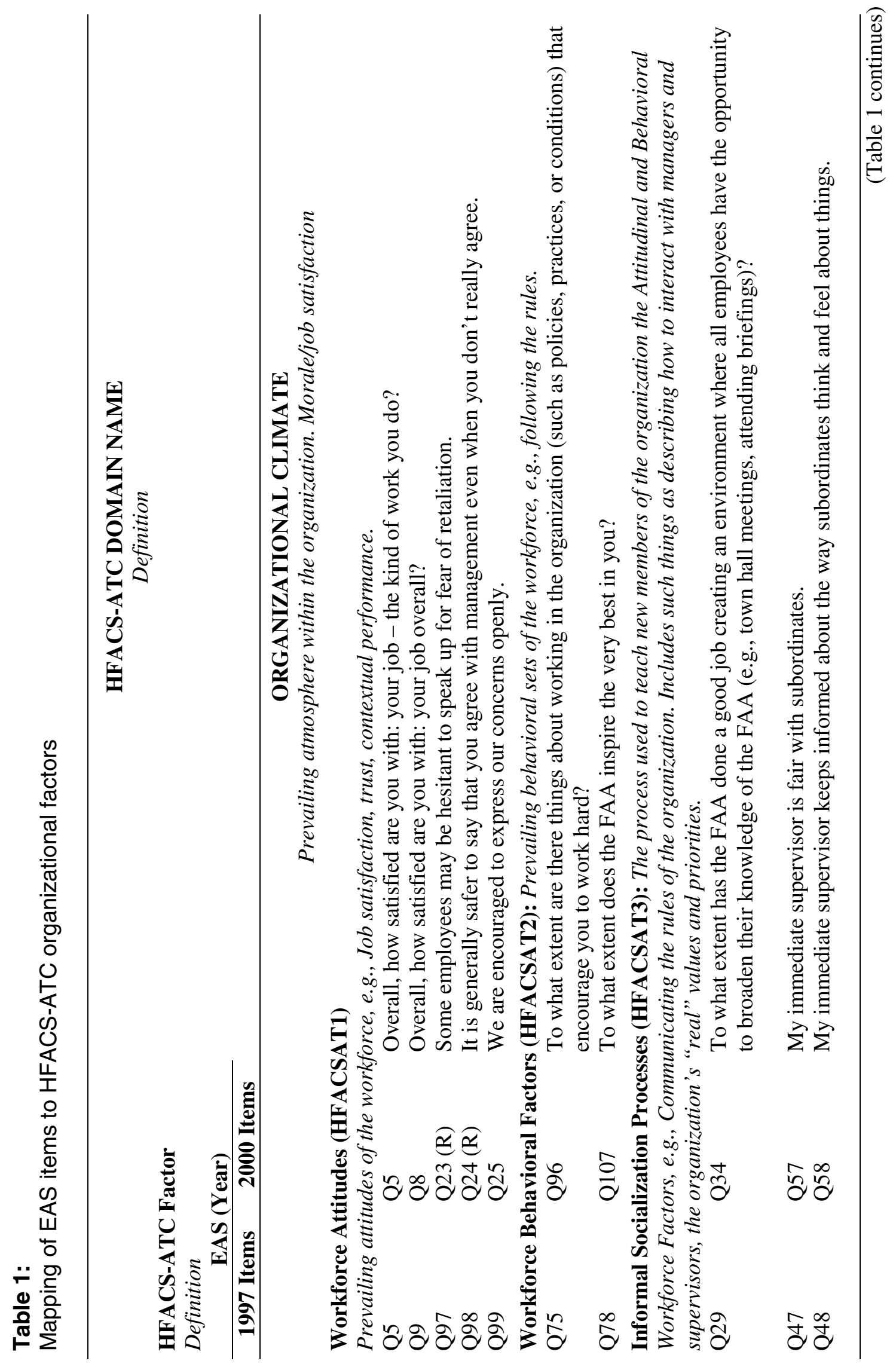




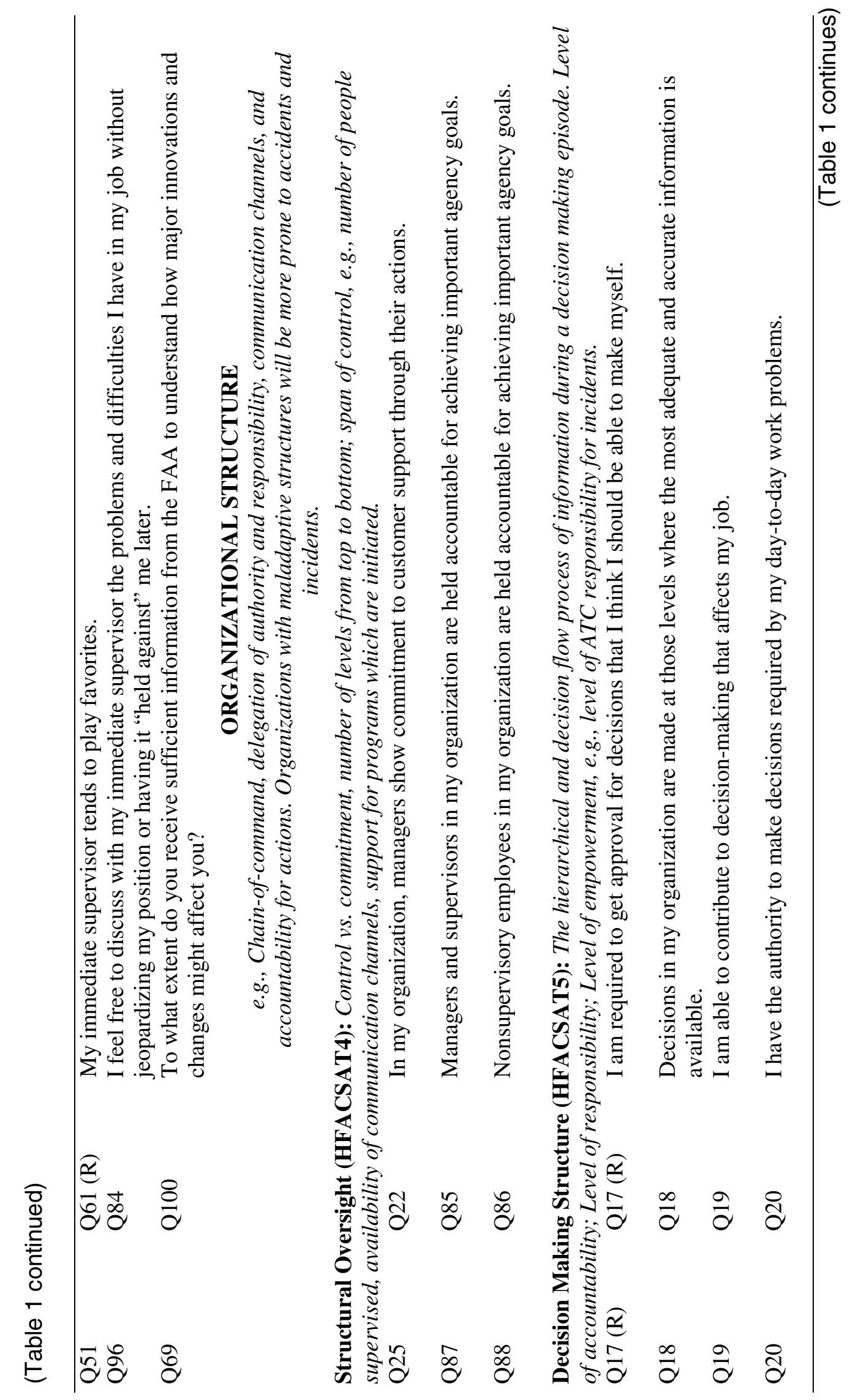



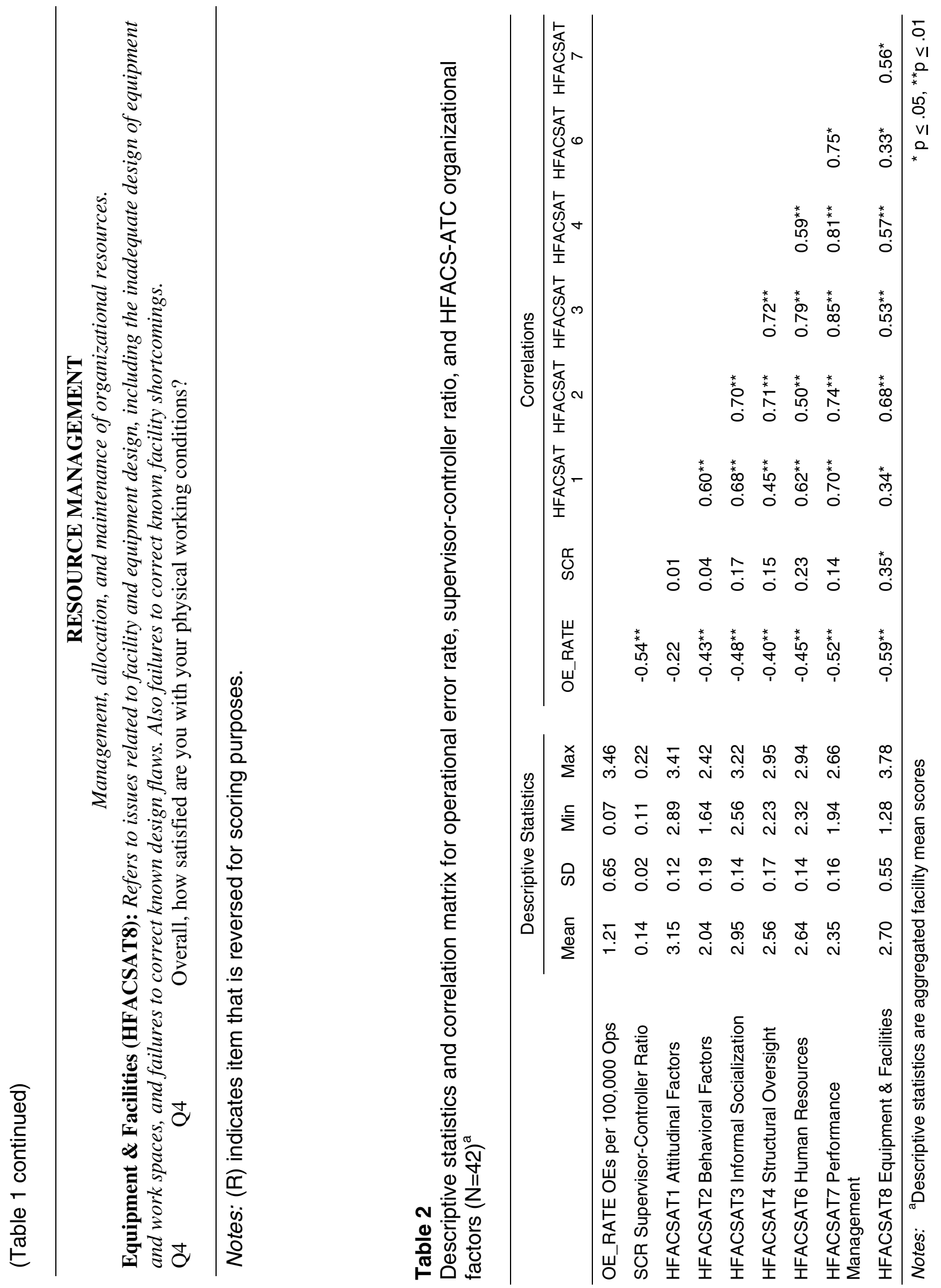
Although there is no absolute cut-off, scales with alphas of less than about .5 to .6 are not commonly used in research, as the scores on such scales are viewed as unreliable.

There were multiple items from both iterations of the EAS related to the HFACS-ATC organizational climate factor. Two EAS items specifically assessed job satisfaction, and three directly assessed employee trust. A scale to represent the workforce attitudes (HFACSAT1; Cronbach's $\alpha=.73$ ) was constructed from these five items. The underlying hypothesis was that facilities with higher satisfaction and trust were more likely to have lower error rates. Another aspect of organizational climate is the extent to which employees were willing to work hard. Two items from the EAS addressed this facet of the facility organizational climate (HFACSAT2; Cronbach's $\alpha=.67$ ), with the underlying hypothesis that facilities with higher levels of willingness to work hard would have lower OE rates. How employees are socialized into the organization plays a role in determining the organizational climate. Six items were identified from the EAS related to the informal socialization process (HFACSAT3; Cronbach's $\alpha=.81$ ). The underlying hypothesis for these items was that facilities with more positive perceptions of informal socialization processes would have lower error rates.

The organizational structure factor of the HFACSATC model was represented by two scales derived by combining EAS items. First, three EAS items referring to managerial accountability and commitment to customer support were combined to represent general supervision (HFACSAT4; Cronbach's $\alpha=.58$ ). We expected that facilities with more positive perceptions of general supervision would have lower OE rates. Second, four EAS items specifically focused on empowerment were used to represent decision-making structure (HFACSAT5), with the expectation that facilities with higher levels of perceived empowerment would have lower error rates. However, this "decision-making structure" scale was dropped from the analysis due to poor reliability (Cronbach's $\alpha=.25$ ).

The policies and procedures facet of the organization was reflected in two scales constructed from the EAS. Six EAS items addressed human resources management policies such as training and promotion opportunity (HFACSAT6; Cronbach's $\alpha=.68$ ). As with the other HFACS-ATC scales, we hypothesized that facilities with more positive perceptions of human resources management policies would have lower error rates. Five EAS items focused on performance management (HFACSAT7; Cronbach's $\alpha=.67$ ). We hypothesized that facilities with more positive perceptions of performance management would also likely experience lower error rates. Finally, resource management was reflected by a single scale addressing the quality of equipment and facilities. A single EAS item was used to represent employee perceptions of the quality of equipment and facilities (HFACSAT8), with the expectation that more positive perceptions would be reflected in lower facility error rates. Scale scores were calculated for each respondent. The six reliable, multiitem scales and HFACSAT7 (a single item scale) were then aggregated by year and facility. The resulting data file included facility identifier, number of respondents, and the facility mean scores on the seven HFACS-ATC scales (HFACSAT1 to HFACSAT4, HFACSAT6 to HFACSAT8) by year and facility.

Employment data extracted from the FAA's CPMIS were used to estimate the supervisor-to-controller ratio (SCR) in 1997 and 2000 for each center. The SCR was computed as the ratio of the number of Operations Supervisors to the total number of Certified Professional Controllers and controllers in training at each center at the end of calendar years 1997 and 2000. The SCR represented an objective measure of an aspect of the organizational structure.

\section{Error data and analyses}

Operational error data were extracted from the National Airspace Incident Monitoring System (NAIMS). SCR and OE (errors per 100,000 operations) were matched by year and center with the aggregated HFACS-ATC scale data file created for this analysis. The $\mathrm{OE}$ rate was regressed on the seven mean HFACS-ATC scale scores and the SCR. SPSS $®$ for Windows (Version 10.0.7; SPSS, Inc., 1999) was used for all file manipulations and statistical analyses.

\section{RESULTS}

Descriptive statistics across centers and the correlation matrix are displayed in Table 2 . The correlations between operational error rate (OE_RATE) and the hypothesized predictors were all negative and significant. The correlation between SCR and OE_RATE was -.54 ( $p \leq .001$; Figure 2$)$. In other words, facilities with about 1 supervisor for every 6-7 controllers (SCR $=.14$ to .17$)$ had lower error rates than facilities with 1 supervisor for every 8-10 controllers ( $\mathrm{SCR}=.10$ to .12). The moderate to moderately large correlations between the HFACS-ATC factors suggested that collinearity might be problem for the analysis. Collinearity refers to the degree to which the predictors are related to one another. When the predictors are highly related to one another, the information each provides 


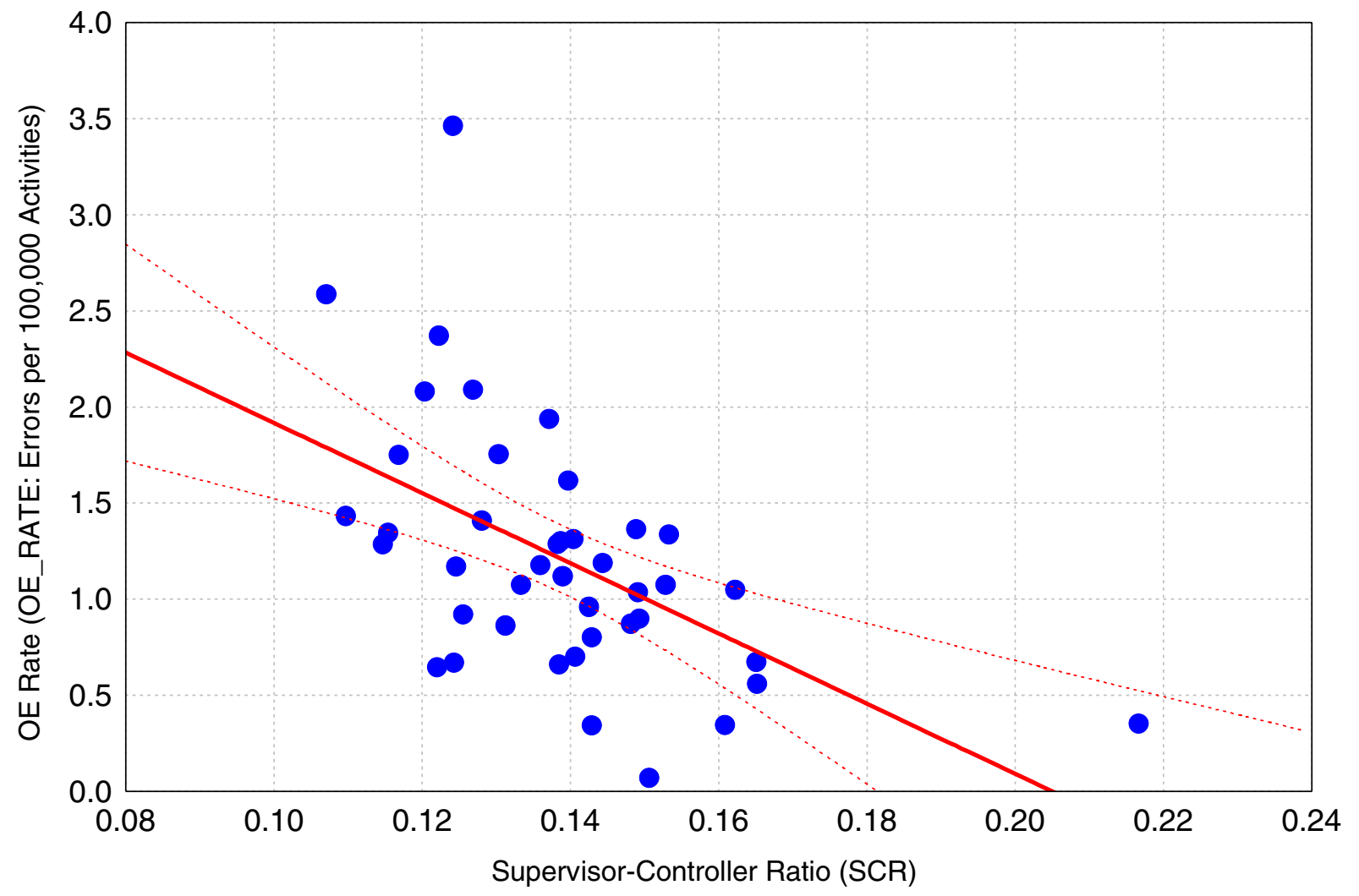

Figure 2: Correlation $(r=-.54, p \leq .001)$ between Supervisor-Controller Ration (SCR) \& Operational Error Rate (OE_RATE)

may be duplicated by the other predictors. As a result, a regression analysis based on highly correlated predictors will be unstable, as one predictor could easily be substituted for another. Therefore, in view of the apparent collinearity among the predictors, regression diagnostics were examined during the course of the analysis.

The results of the stepwise regression of the seven HFACS-ATC scale scores and SCR on the operational error rate are shown in Table 3. Stepwise regression is a technique for identifying the optimally weighted variables from a given set that best predict the criterion (OE_RATE in this instance). Regression diagnostics provided little evidence of problematic collinearity. Variance inflation factor (VIF) scores, a commonly used regression diagnostic, ranged from 1.143 to 1.622 for the three predictor scales that comprised the final model. VIF is equal to 1.0 when the predictors are independent and have no correlation with one another; a value of 10 or greater is often used as a benchmark indicating problematic collinearity among the predictors. VIF scores near 1 indicated that the optimally weighted set of variables that best predicted OE_RATE was stable and interpretable.
Overall, the supervisor-controller ratio (SCR), employee perceptions of how performance was managed in the facility (HFACSAT7), and employee perceptions of the quality of equipment and facilities (HFACSAT8) accounted for $51 \%$ (Adjusted $R^{2}=$ $.505, F(3,38)=14.925, p \leq .001)$ of the variance in 1997 and 2000 operational error rates across the 21 centers. The other factors did not meet the statistical criteria for inclusion in the final model.

The adjusted $R^{2}$ is a conservative estimate of the relationship between the predictors (SCR, HFACSAT7, HFACSAT8) and OE_RATE. The adjusted $R^{2}$ indicates how well OE_RATE can be predicted from the combination of weighted variables. An $R^{2}$ of 1.00 indicates that the criterion (OE_RATE) is perfectly predicted from SCR, HFACSAT7, and HFACSAT8. Conversely, an $R^{2}=0$ indicates that OE_RATE could not be predicted at all from SCR, HFACSAT7, and HFACSAT8. An $R^{2}$ of about .3 is very common in the social sciences, particularly in attitude-related research. An $R^{2}$ of .5 is much less common, and indicates that supervisor-controller ratio, employee perceptions of how performance is 


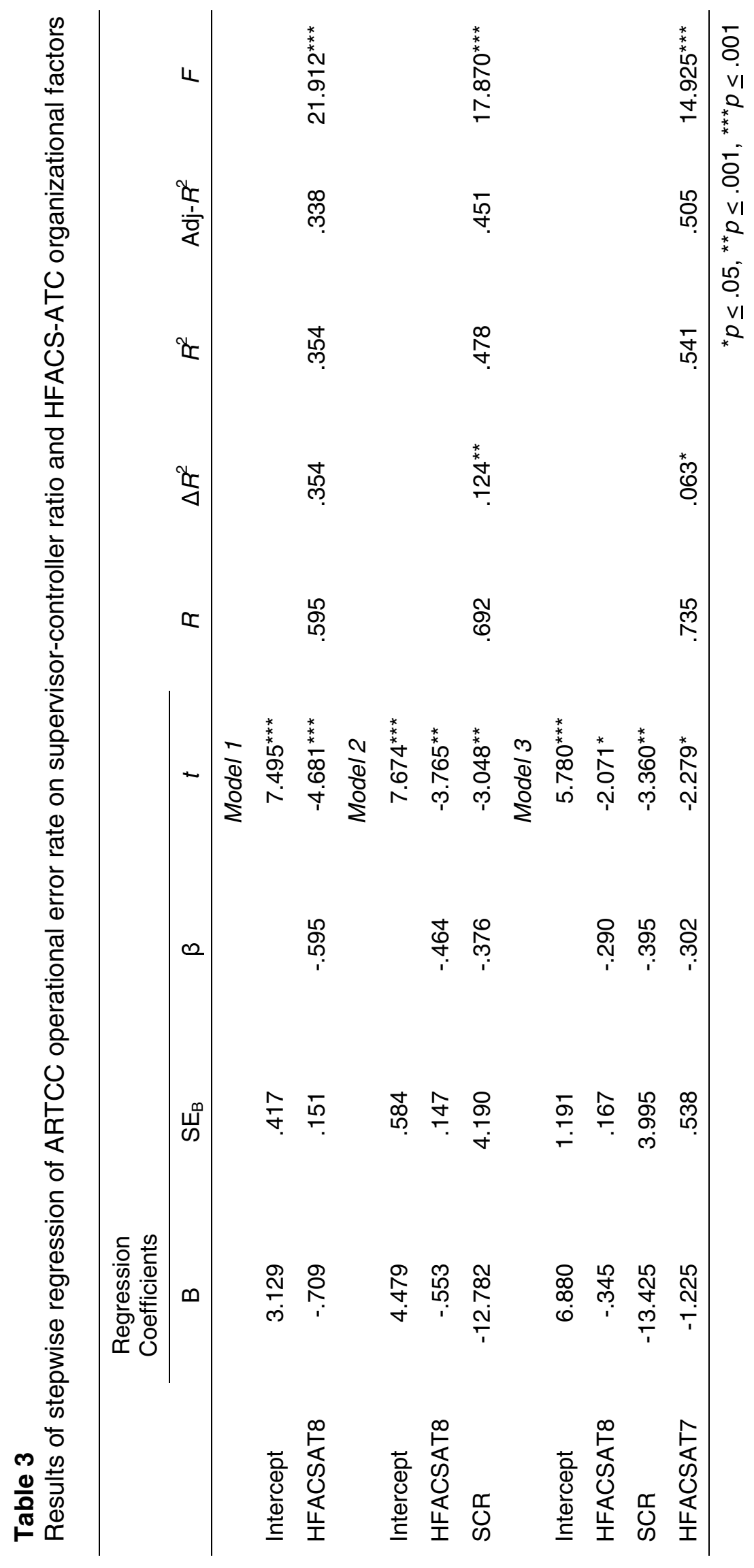


managed and the facilities and equipment have some relationship to the operational error rate at each en route center.

\section{DISCUSSION}

The results of this descriptive study suggest that organizational factors might influence the operational error rate in en route air traffic control at the facility level. This conclusion provides support for including organizational factors in the analysis of operational errors as suggested by HFACS-ATC. The regression analysis also suggests that span-of-control, as represented by the supervisor-to-controller ratio, may be related to en route facility operational error rates.

On the one hand, the analysis indicated that both subjective and objective measures might be useful in explaining differences in error rates between centers. Similar results have been found in examining organizational and work unit attitudes towards safety and accidents in other settings. For example, Zohar (2000) demonstrated an empirical link between perceptions of organizational safety climate and objective injury data. Similarly, Thompson, Hilton, and Witt (1997) demonstrated how perceptions of organizational climate and management roles might affect safety-related outcomes. The measures drawn from the EAS reflect subjective perceptions of equipment and performance management. In contrast, the SCR represents an objective, structural characteristic of each center. Overall, the present analysis suggests that it would be fruitful for human factors investigations of operational errors in air traffic control to take into account subjective perceptions of the organizational climate, including perceptions of safety, as well as objective characteristics of the organizational structure.

On the other hand, the study is descriptive, and it is unlikely that future operational error rates at a particular facility can be predicted from past measures of employee attitudes or supervisor-controller ratios. Moreover, the results of this analysis are not consistent with those reported by CNAC (1995) with respect to supervisor-controller ratio. In that study, staffing ratio, based on mid-year figures, was regressed on the yearly average error rate (CNAC, 1995, p. 94). It is not clear from the description whether the averages were computed across facilities, across years, or both. Consequently, it is unclear as to how to interpret the results of the present study with respect to the CNAC study. Further research is clearly needed to explore and explain any differences as well as to replicate the findings of the present study.
Finally, it must be noted that this study did not examine relationships between attitudes and errors at the level of the individual controller. The unit of analysis for this study was the facility. The attitudinal predictors were composite, aggregated average scores at the facility level created from anonymous survey data. EAS data cannot be matched with OE data, as the EAS is anonymous, and the final OE reports do not identify the involved controller(s). The results of this study cannot be used in any way to predict the likelihood of an individual controller being involved in an operational error. However, they do underscore the need to collect data at multiple levels of analysis, including organizational characteristics as well as information on the individual controllers involved in errors. While the organizational data might or might not be relevant to any single $\mathrm{OE}$, patterns across errors and over time might be found. Identification of such patterns, in turn, might guide interventions and risk mitigation strategies as the FAA actively seeks to reduce the incidence of en route operational errors.

\section{REFERENCES}

Air Traffic Services. (2000, December). Air Traffic Services performance plan, FY2001-2003. Washington, DC: Federal Aviation Administration Office of the Associate Administrator for Air Traffic Services. (Available from http:// www.apo.data.faa.gov/dirplans/).

Broach, D. (1999, May). An examination of the relationship between air traffic controller age and en route operational errors. Paper presented at the 10th International Symposium on Aviation Psychology, Columbus, OH.

Center for Naval Analyses Corporation. (1995, November). Analysis of operational errors for air route traffic control centers. Volume I: Final report. (IPR 955108). Alexandria, VA: The Center for Naval Analyses Corporation Institute for Public Research.

Cronbach, L. J. (1951). Coefficient alpha and the internal structure of tests. Psychometrika, 16, 297-334.

Della Rocco, P.S. (Ed.). The role of shift work and fatigue in air traffic control operational errors and incidents. (DOT/FAA/AM-99/2). Washington, DC: Federal Aviation Administration Office of Aerospace Medicine. ${ }^{1}$

${ }^{1}$ FAA Office of Aerospace Medicine technical reports are available on-line in full text at http://www.cami.jccbi.gov/ aam-400A/Abstracts/Tech_Rep.htm 
Della Rocco, P. S., Cruz, C. E., \& Clemens, J. A. (1999). Operational errors/deviations and shift work in air traffic control. In Della Rocco, P.S., (Ed.). The role of shift work and fatigue in air traffic control operational errors and incidents. (DOT/FAA/AM-99/2). Washington, DC: Federal Aviation Administration Office of Aerospace Medicine. ${ }^{1}$

Department of Transportation Office of the Inspector General. (2000, December). Actions to reduce operational errors and deviations have not been effective. (AV-2001-011). Washington, DC: Author. (Available from http://www.oig.dot.gov).

Department of Transportation Office of the Inspector General (2002, March). FAA's fiscal year 2003 budget request. (CC-2002-125). Washington, DC: Author. (Available from http://www.oig.dot.gov).

Endsley, M. R., \& Rodgers, M. D. (1997). Distribution of attention, situation awareness, and workload in a passive air traffic control task: Implications for operational errors and automation. (DOT/FAA/AM-97/ 13). Washington, DC: Federal Aviation Administration Office of Aerospace Medicine. ${ }^{1}$

Federal Aviation Administration. (2002, February). Air traffic control. (FAA Order $7110.65 \mathrm{~N}$ ). Washington, DC: Author. (Available from http:// www.faa.gov/atpubs/index.htm).

Fisher, J. (2001, March). Air traffic issues: Testimony before the Committee on Appropriations, Subcommittee on Transportation and Related Agencies, United States House of Representatives. Alexandria, VA: Federal Managers Association Federal Aviation Administration Conference. (Available from http://www.fedmanagers.org/testimony.htm).

Kinney, G. (1977). The human element in air traffic control: Observations and analyses of the performance of controllers and supervisors in providing ATC separation services. (MITRE Technical Report MTR-7655). McLean, VA: The MITRE Corporation.

Reason, J. (1990). Human error. New York: Cambridge University Press.

Rodgers, M., Mogford, R., \& Mogford, L. (1998). The relationship of sector characteristics to operational errors. (DOT/FAA/AM-98/14). Washington, DC: Federal Aviation Administration Office of Aerospace Medicine. ${ }^{1}$
Rodgers, M. D., \& Nye, L. G. (1993). Factors associated with severity of operational errors at air route traffic control centers. In M. D. Rodgers (Ed.), An examination of the operational error database for air route traffic control centers. Washington, DC: Federal Aviation Administration Office of Aerospace Medicine. ${ }^{1}$

Scarborough, A. \& Pounds, J. (2001). Retrospective human factors analysis of ATC operational errors. Paper presented at the 11th International Symposium on Aviation Psychology, Columbus, $\mathrm{OH}$.

Schneider, A. (2001, February). An analysis of the correlation between enroute operational errors and employee attitudes. Unpublished master's thesis, Embry-Riddle Aeronautical University Extended Campus, Oklahoma City Resident Center.

Schroeder, D. J., \& Nye, L. G. (1993). An examination of the workload conditions associated with operational errors/deviations at air route traffic control centers. In M. D. Rodgers (Ed.), An examination of the operational error database for air route traffic control centers. Washington, DC: Federal Aviation Administration Office of Aerospace Medicine. ${ }^{1}$

Shappell, S. A., \& Wiegmann, D. A. (2000). The Human Factors Analysis and Classification SystemHFACS. (DOT/FAA/AM-00/7). Washington, DC: Federal Aviation Administration Office of Aerospace Medicine. ${ }^{1}$

SPSS, Inc. (1999). SPSS ${ }^{\circ}$ Base 10.0 user's guide. Chicago, IL: Author.

Thompson, R., Hilton, T., Twohig, P., Pagnini, C., Park, H., King, J., Malone, M., Thompson, D., \& Thompson, J. (2000, March). Results of the 1997 Employee Attitude Survey. (Memorandum Report). Oklahoma City, OK: FAA Civil Aerospace Medical Institute Human Resources Research Division.

Thompson, R., Hilton, T., \& Witt, L. A. (1997). Where the safety rubber meets the shop floor: A confirmatory model of management influence on workplace safety. (DOT/FAA/AM-97/8). Washington, DC: Federal Aviation Administration Office of Aerospace Medicine. ${ }^{1}$

Zohar, D. (2000). A group-level model of safety climate: Testing the effect of group climate on microaccidents in manufacturing jobs. Journal of Applied Psychology, 85, 587-596. 
